\title{
Complications of cranioplasty following decompressive craniectomy: analysis of 62 cases
}

\author{
M. Reid Gooch, B.S., Greg E. Gin, M.S., Tyler J. Kenning, M.D., \\ AND John W. German, M.D.
}

Division of Neurosurgery, Albany Medical Center, Albany, New York

\begin{abstract}
Object. Decompressive craniectomy is a potentially life-saving procedure used in the treatment of medically refractory intracranial hypertension, most commonly in the setting of trauma or cerebral infarction. Once performed, surviving patients are obligated to undergo a second procedure for cranial reconstruction. The complications following cranial reconstruction are not well described in the literature and may very well be underreported. A review of the complications would suggest measures to improve the care of these patients.

Methods. A retrospective chart review was undertaken of all patients who had undergone cranioplasty during a 7-year period. Demographic data, indications for craniectomy, as well as preoperative, intraoperative, and postoperative parameters following cranioplasty, were recorded. Perioperative and postoperative complications were also recorded. Patients were classified as having no complications, any complications, and complications requiring reoperation. The groups were compared to identify risk factors predictive of poor outcomes.

Results. The authors identified 62 patients who had undergone cranioplasty. The immediate postoperative complication rate was $34 \%$. Of these, 46 patients did not require reoperation and 16 did. Of those requiring reoperation, 7 were due to infection, 2 from wound breakdown, 2 from intracranial hemorrhage, 3 from bone resorption, and 1 from a sunken cranioplasty, and 1 patient's cranioplasty procedure was prematurely ended due to intraoperative hypotension and bradycardia. The only factor statistically associated with need for reoperation was the presence of a bifrontal cranial defect (bifrontal: 8 [67\%] of 12, requiring reoperation; unilateral: 8 [16\%] of 49 requiring reoperation; $\mathrm{p}<0.01)$

Conclusions. Cranioplasty following decompressive craniectomy is associated with a high complication rate. Patients undergoing a bifrontal craniectomy are at significantly increased risk for postcranioplasty complications, including the need for reoperation. (DOI: 10.3171/2009.3.FOCUS0962)
\end{abstract}

\section{KEY WORDS • cranioplasty • craniectomy • cranial reconstruction • cerebral decompression • intracranial hypertension}

$\mathrm{D}$ ECOMPRESSIVE craniectomy is a potentially lifesaving procedure used in the treatment of medically refractory intracranial hypertension, most commonly in the setting of trauma or large-vessel infarct and less frequently in the settings of aneurysmal subarachnoid hemorrhage, intraoperative brain swelling, and encephalitis. ${ }^{21,59}$ Decompressive craniectomy, however, remains controversial. Its efficacy is currently being investigated with respect to survival and quality of life in multicenter, prospective, randomized trials in the setting of traumatic brain injury ${ }^{22}$ and middle cerebral artery infarction. ${ }^{27,66}$

Once patients undergo decompressive craniectomy, those who survive are obligated to undergo a second procedure for surgical cranial reconstruction, that is, cranioplasty. Much of the modern literature regarding cranioplasty following decompressive craniectomy is based on case series that emphasize the technical aspects of the procedure such as the use of materials, , 2,3, , 10,12,14,26,30,33,35,50$52,54,55,60,63,68,70,71$ the use of techniques to store the bone flap prior to reconstruction, ${ }^{16,19,24,25,43,48,49,72}$ the timing of sur- gical intervention, ${ }^{6,37}$ or other specific modifications to either the craniectomy or cranioplasty procedure, which may influence the cranioplasty. ${ }^{20,28,34,36,38,41,47,67}$ There are relatively few modern-day large clinical series describing the clinical outcomes and perioperative complications of cranioplasties in the setting of nonpenetrating traumatic brain injury and large vessel infarction. $.^{40,42} \mathrm{Com}-$ plications after cranial reconstruction, often viewed as a straightforward neurosurgical procedure, may very well be underreported. Furthermore, traditional neurosurgical dictums regarding certain aspects of cranioplasty such as timing of surgery may not be appropriate in the modern era of neurosurgical care. A review of the complications would suggest measures to improve the care of these patients.

In the current study, our goal was to provide a complete review of all perioperative complications, defined as any potentially adverse event within 30 days of surgery, as well as identify any risk factors that may be associated with the need for reoperation after a primary cranioplasty. 
M. R. Gooch et al.

\section{Methods}

The study was approved by the institutional review board of Albany Medical Center, a Level 1 trauma, tertiary care, teaching hospital. After approval, the billing and discharge databases of the neurosurgical service were reviewed to identify all patients who had undergone cranioplasty following a decompressive craniectomy during a 7-year period (January 1, 2002-December 31, 2008). This series only included patients who underwent craniectomies for cerebral swelling and excluded those undergoing craniectomy for meningioma resection and craniosynostosis. Once identified, the available hospital charts and clinic records were reviewed retrospectively to abstract relevant data.

Abstracted data included age at time of cranioplasty (years), sex (male or female), medical comorbidities (hypertension, diabetes, and tobacco use), indications for craniectomy (trauma, stroke, infection, and intraoperative swelling), laterality of craniectomy (bilateral, unilateral, or bifrontal), time between craniectomy and cranioplasty (days), type of prosthesis if used (titanium, methylmethacrylate, or porex), storage of bone flap if used (subcutaneous or tissue bank), operative time (minutes), identification of intraoperative CSF leak (yes or no), estimated blood loss (ml), intraoperative fluid administration (ml), length of stay after cranioplasty (days), and disposition before and after the cranioplasty (home, hospital, or inpatient nursing facility).

Any potentially adverse medical or surgical events identified within 30 days of surgery were recorded as early complications. Late complications were unsatisfactory events directly related to the cranioplasty occurring $>30$ days postoperation. Patients were classified as having no complication, any complication, and complication requiring reoperation. Specifically, our 2 outcomes of interest were complications after cranioplasty and the need for reoperation after cranioplasty. Both variables were dichotomized, and all patient- and surgery-related factors were assessed as risk factors for each of the 2 outcomes of interest via bivariate analysis. Chi-square analysis and the Fisher exact test were used to assess the association between the categorical risk factors and the outcomes. The Wilcoxon rank-sum test was used to assess if the distribution of the continuous variables was different among those who did and those who did not have the outcomes of interest. To assess complication rates associated with time to cranioplasty, patients were divided into quartiles, and ORs were calculated. All tests were 2-tailed. All associations were assessed at a level of 0.05 of statistical significance. Statistical analysis was performed using STATA 10 software (StataCorp LP).

\section{Results}

We identified 109 patients who had undergone a cranioplasty following cerebral decompression via craniectomy. Of these, 23 charts were incomplete for the purpose of this study, and 24 patients were lost to follow-up in the early postoperative period. As a result, 62 patients were identified who had undergone a decompressive craniec-
TABLE 1: Demographic and operative details in 62 patients undergoing craniectomy and cranioplasty

\begin{tabular}{lc}
\hline \multicolumn{1}{c}{ Characteristic } & No. of \\
& Patients (\%)* \\
\hline $\begin{array}{l}\text { no. of patients } \\
\text { male }\end{array}$ & 62 \\
female & $34(55)$ \\
craniectomy & $28(45)$ \\
mean age (yrs) & \\
indication & $31.5 \pm 2.4$ \\
trauma & \\
stroke & $41(66)$ \\
infection & $15(24)$ \\
intraop swelling & $2(3)$ \\
type & $4(6)$ \\
unilat & \\
bifrontal & $49(79)$ \\
bilat & $12(19)$ \\
cranioplasty & $1(2)$ \\
mean age (yrs) & \\
type of prosthesis & $31.9 \pm 2.4$ \\
autologous & \\
titanium & \\
methylmethacrylate & \\
mean no. of days btwn craniectomy \& cranioplasty & $133 \pm 18.2$ \\
mean op room time (min) \\
mean estimated blood loss (ml) \\
mean intraop intravenous fluids (ml) \\
mean length of stay (days) & $173 \pm 10$ \\
\hline & $238 \pm 28$ \\
& $1881 \pm 138$ \\
& $11 \pm 2.1$ \\
\hline
\end{tabular}

* Unless otherwise indicated, mean values are presented as the means \pm SEMs.

tomy and subsequent cranioplasty with a minimum of 4 months of follow-up. Even among this population, some variables could not be reliably extracted from the medical records including medical comorbidities, disposition before and after cranioplasty, and intraoperative CSF leakage. The baseline patient characteristics and perioperative factors are shown in Table 1 . The majority of the patients in this review were male (34 [55\%]), and the most common indication for craniectomy was trauma (41 [66\%]). Other reasons for decompressive craniectomy included stroke, infection, and intraoperative swelling. Most craniectomies were unilateral (49 [79\%]). In addition, 12 patients (19\%) underwent a bifrontal craniectomy, and 1 (2\%) underwent a bilateral decompression. Regarding the cranioplasty procedure, the overwhelming majority of repairs used autologous bone (57 [92\%]), and all autologous bone was stored in a tissue bank. Titanium and methylmethacrylate repairs were performed much less frequently (2 [3\%] and 3 [5\%] cases, respectively).

\section{Surgical Complications}

Perioperative and postoperative complications are summarized in Table 2. Of the 62 patients undergoing 
Complications of cranioplasty after decompressive craniectomy

TABLE 2: Complications in 62 patients undergoing craniectomy and cranioplasty*

\begin{tabular}{|c|c|c|c|}
\hline \multirow[b]{2}{*}{ Complication } & \multicolumn{3}{|c|}{ No. of Patients (\%) } \\
\hline & $\begin{array}{c}\text { Early ( } \leq 30 \\
\text { days postop) }\end{array}$ & $\begin{array}{l}\text { Late (>30 } \\
\text { days postop) }\end{array}$ & $\begin{array}{l}\text { No. Requiring } \\
\text { Reop }\end{array}$ \\
\hline wound & $3(4.8)$ & $6(9.7)$ & 9 \\
\hline infection & $2(3.2)$ & $5(8.1)$ & 7 \\
\hline dehiscence & $1(1.6)$ & $1(1.6)$ & 2 \\
\hline hematoma & $2(3.2)$ & 0 & 2 \\
\hline epidural & $1(1.6)$ & 0 & 1 \\
\hline subdural & $1(1.6)$ & 0 & 1 \\
\hline bone resorption & 0 & $4(6.5)$ & 3 \\
\hline sunken bone plate & 0 & $1(1.6)$ & 1 \\
\hline $\begin{array}{l}\text { intraop hemodynamic } \\
\text { instability }\end{array}$ & $1(1.6)$ & 0 & 1 \\
\hline status epilepticus & $1(1.6)$ & 0 & 0 \\
\hline hydrocephalus & $1(1.6)$ & 0 & 0 \\
\hline deep vein thrombosis & $2(3.2)$ & 0 & 0 \\
\hline upper extremity & $1(1.6)$ & 0 & 0 \\
\hline \multirow[t]{2}{*}{ lower extremity } & $1(1.6)$ & 0 & 0 \\
\hline & 0 & 0 & 0 \\
\hline total & $10(16.1)$ & $11(17.7)$ & 16/21 (76.2) \\
\hline
\end{tabular}

* Of 62 patients, 21 (33.8\%) had some complication and 16 (25.8\%) required a reoperation.

cranioplasty, 41 (66\%) experienced no complications and $21(34 \%)$ experienced at least 1 complication. Complications included infection (7), wound dehiscence (2), epidural hematoma (1), subdural hematoma (1), bone resorption (4) which was diagnosed clinically and confirmed on CT scanning, sunken bone plate (1), status epilepticus (1), hydrocephalus (1), deep vein thromboses (2), and intraoperative bradycardia and hypotension necessitating a premature end to the cranioplasty procedure (1). Ten patients (16.1\%) had early complications and $11(17.7 \%)$ had late complications. After statistical analysis, the only measured variable found to be significantly associated with complication after cranioplasty was a bifrontal defect compared with a unilateral defect (bifrontal: 8 [67\%] of 12, with complications; unilateral: 13 [27\%] of 49, with complications; $p<0.05)$. Suffering a postoperative complication resulted in a longer duration of inpatient hospitalization, but this difference was not statistically significant (uncomplicated: mean 5.0 days vs any complication: mean 7.4 days, $p>0.05$ ).

\section{Complications Requiring Reoperation}

Complications requiring reoperation are summarized in Table 2. Sixteen patients (26\%) had complications that required an additional surgery to address their primary cranioplasty site. Such complications included infection, wound dehiscence, intracranial hemorrhage, bone resorption, and sunken bone plate. In 1 patient, the initial procedure was aborted midoperation due to hemodynamic in-
TABLE 3: Data regarding reoperation and laterality

\begin{tabular}{lcc}
\hline \multirow{2}{*}{ Characteristic } & \multicolumn{2}{c}{ No. of Patients (\%) } \\
\cline { 2 - 3 } & No Reop & Reop \\
\hline $\begin{array}{l}\text { no. of patients } \\
\text { laterality of cranioplasty }\end{array}$ & $46(74)$ & $16(26)$ \\
$\quad$ unilat & $41(84)$ & $8(16)$ \\
bifrontal & $4(33)$ & $8(67)$ \\
bilat & $1(100)$ & $0(0)$ \\
no. of days btwn craniec- & $129 \pm 22$ & $143 \pm 34$ \\
tomy \& cranioplasty* & & \\
\hline
\end{tabular}

* Presented as the means \pm SEMs.

stability. After statistical analysis, the only variable found to be significantly associated with a need for reoperation was the presence of a bifrontal cranial defect (bifrontal: 8 [67\%] of 12 requiring reoperation; unilateral: 8 [16\%] of 49 requiring reoperation; $p<0.01$ ) (Table 3 ).

\section{Time to Cranioplasty}

The 62 patients who underwent cranioplasty were divided into 4 groups, each containing approximately the same number of patients, based on duration of time between craniectomy and cranioplasty. Odds ratios calculating the likelihood of complications and complications requiring reoperation with respect to timing of cranioplasty are presented in Table 4. For complications and complications requiring reoperation, ORs were highest in the 100- to 136-day group (OR 1.67 and 3, respectively).

\section{Discussion}

Cranioplasty following decompressive craniectomy is a conceptually intuitive procedure from the perspective of safety and cosmesis. More recent reports have suggested that the procedure may help optimize neurological recovery, both physiologically and/or clinically. $1,4,11,13,15,18,23,31,32,44-46,57,58,61,64,65,69$ However, there is no specific technique or material that has consistently stood alone as superior, and postoperative complication rates vary widely. ${ }^{62}$ In the modern era, most reports in the literature regarding cranioplasty have focused on technical aspects of the procedure and have not emphasized overall

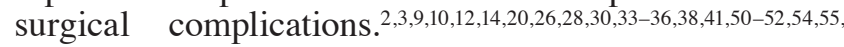
$60,63,67,68,70,71$ Because decompressive craniectomy is now being reevaluated in large, prospective, randomized trials,,$^{22,27,66}$ an analysis of complications for cranioplasty is particularly important. As almost all patients surviving a decompressive craniectomy will require cranioplasty, the complications of this second operative intervention should be acknowledged.

\section{Complications Following Cranioplasty}

The current report suggests that cranioplasty following decompressive craniectomy is associated with a high complication rate $(33.8 \%)$. Of those patients who did experience complications, 5 (24\%) of the 21 did not require 
M. R. Gooch et al.

TABLE 4: Data regarding time between craniectomy and craniotomy and ensuing complications

\begin{tabular}{|c|c|c|c|c|c|}
\hline \multirow[b]{2}{*}{$\begin{array}{l}\text { No. of Days Btwn Craniectomy } \\
\text { \& Cranioplasty }\end{array}$} & \multirow[b]{2}{*}{ No. of Patients } & \multicolumn{2}{|c|}{ Complications } & \multicolumn{2}{|c|}{ Complications Requiring Reoperation } \\
\hline & & No. $(\%)$ & OR & No. (\%) & OR \\
\hline $0-48$ & 16 & $6(38)$ & 0 & $4(25)$ & 0 \\
\hline $49-99$ & 15 & $3(20)$ & 0.42 & $0(0)$ & - \\
\hline $100-136$ & 16 & $8(50)$ & 1.67 & $8(50)$ & 3 \\
\hline$\geq 137$ & 15 & $4(27)$ & 0.61 & $4(27)$ & 1.1 \\
\hline
\end{tabular}

a subsequent operation. However, these complications could not all be classified as "minor." Specifically, one such patient was found to be in status epilepticus immediately postoperatively. Of the patients with complications, $76 \%$ required another operation to address their previous cranioplasty. Such complications included infection, bone resorption, wound dehiscence, sunken bone flap, hematoma, and intraoperative hemodynamic instability necessitating a premature end to the primary cranioplasty procedure. Of note, our infection rate (11.3\%) appears to be similar to that previously reported in large series of patients undergoing cranioplasty. ${ }^{7,29,40,42}$

\section{Complications Requiring Reoperation Following Cranioplasty}

In the current analysis, complications requiring reoperation occurred in 16 patients $(26 \%)$ and in $76 \%$ of those who had any complication (16 of 21). This overall reoperative complication rate is surprisingly high, considering the perceived straightforward nature of this procedure.

In our series, all patients who experienced wound complications as defined by infection and wound dehiscence required reoperation. Three of these patients initially presented with wound dehiscence without gross evidence of infection. All 3 were treated with primary closure. Two of the patients received scalp tissue expanders prior to this procedure. The third patient underwent uneventful revision of his scalp flap, but bacterial cultures taken from the operating room eventually revealed methicillin-resistant Staphylococcus aureus. He was subsequently treated with intravenous antibiotics. None of these patients was treated by removal of the bone plate. Our review demonstrated that patients undergoing a bifrontal cranioplasty were significantly more likely to have complications. The complications in this group included infection (in 4 patients), wound dehiscence (in 1), sunken bone plate (in 1), resorption (in 1), and hemodynamic instability during cranioplasty (in 1). All complications for these patients led to reoperation. Several factors may have contributed to this observation, including a longer incision in the case of a bifrontal defect, less available temporalis muscle to provide soft-tissue coverage, possible violation of the frontal sinus, and perhaps a longer operative time. Of these, violation of the frontal sinus has previously been described as a definitive risk factor for infection after cranioplasty. ${ }^{5,39}$ Unfortunately, because of the retrospective nature of this study we were unable to reliably quantify any of these potentially contributing variables.

\section{Time to Cranioplasty}

According to traditional neurosurgical dictum, a shorter time from craniectomy to cranioplasty is associated with poor outcome. 17,53,62 While often recommended in neurosurgical texts, the basis of this recommendation is not well cited. The rationale for this waiting period is most likely based on the large series of patients reported by Rish and colleagues ${ }^{56}$ in 1979 . This group found that cranioplasties taking place 1-6 months after craniectomy had the highest complication rate $(7.9 \%)$ and those performed 12-18 months after craniectomy had the lowest complication rate $(4.5 \%)$. The purported advantage of this waiting period includes avoidance of operating on a potentially contaminated wound. ${ }^{56}$ However, because this study included only patients with penetrating head injuries, the results may not apply to patients who have undergone decompressive craniectomy in the setting of nonpenetrating injury. Recently Carvi et al. ${ }^{6}$ and Liang et al. ${ }^{37}$ have suggested that cranioplasty following decompressive craniectomy for blunt injury can be performed sooner than previously suggested. The possible advantages of performing cranioplasty in a more timely fashion may include easier dissection of tissue planes, as well as prevention of negative postcraniectomy sequelae including posttraumatic hydrocephalus, ${ }^{8}$ syndrome of the trephined, ${ }^{31,46}$ or other neurological complications. ${ }^{32,61,64}$

Our analysis in regard to time between craniectomy and cranioplasty revealed a higher risk of both postoperative complications and need for reoperation in those patients treated between 100 and 136 days. It is difficult to rectify this point clinically, and our small number of events in each group limits the strength of any conclusions to be made regarding these data. Most significant may be the fact that those patients treated early (0-48 days) or those treated late ( $\geq 137$ days) did not have a significantly increased risk. This finding, along with the reports by Carvi et al. ${ }^{6}$ and Liang et al., ${ }^{37}$ may negate previous dictum suggesting cranioplasty needing to be performed during a certain time point postcraniectomy. Again, this conclusion is limited and requires further analysis in a prospective study.

\section{Critique of the Current Study}

The current study is a retrospective analysis of the complications of cranioplasty following decompressive craniectomy. Accordingly, the study suffers from all the anticipated deficiencies of a retrospective analysis including loss of patient information, poor follow-up, inconsis- 


\section{Complications of cranioplasty after decompressive craniectomy}

tent operative indications for craniectomy, and inconsistent techniques for cranioplasty. These deficiencies may lead to an inaccurate estimation of the true complication rate.

In an effort to accurately estimate the complication rate, any potentially adverse event in this series was identified as a complication. This method may have falsely inflated the observed complication rate. On the other hand, in a review of cranioplasties in 75 children, Blum et al., ${ }^{5}$ did not identify any complications until 2.5 years postoperatively. Given that our patients were included with only a minimal follow-up of 4 months, it is possible we may actually be underreporting the total number of complications. Despite these limitations, the current study is important as it highlights the fact that a significant number of complications do occur following cranioplasty, including complications that may necessitate reoperation.

\section{Conclusions}

Patients undergoing decompressive craniectomy are obligated to undergo a second procedure for cranial reconstruction. This second surgery has a remarkably high rate of complications. Additionally, patients undergoing bifrontal craniectomies are at a significantly increased risk for postcranioplasty complications including the need for an additional operation. The time between craniectomy and cranioplasty does not appear to be associated with complications; however, our data are too limited to make definitive conclusions as to this point. Prospective studies are needed to further evaluate cranioplasty complications.

\section{Disclaimer}

The authors report no conflict of interest concerning the materials or methods used in this study or the findings specified in this paper.

\section{Acknowledgments}

The authors thank Alan S. Boulos, M.D., Darryl J. Dirisio, M.D., Joseph F. Emrich, M.D., David L. Semenoff, M.D., Yu-Hung Kuo, M.D., PhD., Paul E. Spurgas, M.D., and John B. Waldman, M.D., Department of Neurosurgery, Albany Medical Center, for contributing cases, and Dr. Ashar Ata, Department of Surgery, Albany Medical Center, for statistical analysis.

\section{References}

1. Agner C, Dujovny M, Gaviria M: Neurocognitive assessment before and after cranioplasty. Acta Neurochir (Wien) 144:1033-1040, 2002

2. Aziz TZ, Mathew BG, Kirkpatrick PJ: Bone flap replacement vs acrylic cranioplasty: a clinical audit. Br J Neurosurg 4:417-419, 1990

3. Azmi A, Latiff AZ, Johari A: Methyl methacrylate cranioplasty. Med J Malaysia 59:418-421, 2004

4. Bijlenga P, Zumofen D, Yilmaz H, Creisson E, de Tribolet N: Orthostatic mesodiencephalic dysfunction after decompressive craniectomy. J Neurol Neurosurg Psychiatry 78:430433, 2007

5. Blum KS, Schneider SJ, Rosenthal AD: Methyl methacrylate cranioplasty in children: long-term results. Pediatr Neurosurg 26:33-35, 1997
6. Carvi Y, Nievas MN, Höllerhage HG: Early combined cranioplasty and programmable shunt in patients with skull bone defects and CSF-circulation disorders. Neurol Res 28:139-144, 2006

7. Cheng YK, Weng HH, Yang JT, Lee MH, Wang TC, Chang $\mathrm{CN}$ : Factors affecting graft infection after cranioplasty. J Clin Neurosci 15:1115-1119, 2008

8. Choi I, Park HK, Chang JC, Cho SJ, Choi SK, Byun BJ: Clinical factors for the development of posttraumatic hydrocephalus after decompressive craniectomy. J Korean Neurosurg Soc 43:227-231, 2008

9. Datti R, Cavagnaro G, Camici S: Stainless steel wire mesh cranioplasty: ten years' experience with 183 patients (100 followed up). Acta Neurochir (Wien) 78:133-135, 1985

10. Ducic Y: Titanium mesh and hydroxyapatite cement cranioplasty: a report of 20 cases. J Oral Maxillofac Surg 60:272276, 2002

11. Dujovny M, Agner C, Aviles A: Syndrome of the trephined: theory and facts. Crit Rev Neurosurg 9:271-278, 1999

12. Dujovny M, Aviles A, Anger C: An innovative approach for cranioplasty using hydroxyapatite cement. Surg Neurol 48:294-297, 1997

13. Dujovny M, Fernandez P, Alperin N, Betz W, Misra M, Mafee M: Post-cranioplasty cerebrospinal fluid hydrodynamic changes: magnetic resonance imaging quantitative analysis. Neurol Res 19:311-6, 1997

14. Durham SR, McComb JG, Levy ML: Correction of large (>25 $\mathrm{cm}(2)$ ) cranial defects with "reinforced" hydroxyapatite cement: technique and complications. Neurosurgery 52:842845,2003

15. Erdogan E, Düz B, Kocaoglu M, Izci Y, Sirin S, Timurkaynak E: The effect of cranioplasty on cerebral hemodynamics: evaluation with transcranial Doppler sonography. Neurol India 51:479-481, 2003

16. Flannery T, McConnell RS: Cranioplasty: why throw the bone flap out? Br J Neurosurg 15:518-520, 2001

17. Foster RD, Antonyshyn OM, Lee C, Holland M, Fazl M: Cranioplasty: Indications, techniques, and results, in Schmidek HH (ed): Schmidek and Sweet Operative Neurosurgical Techniques. Philadelphia: WB Saunders, 2000, pp 29-44

18. Gottlob I, Simonsz-Tòth B, Heilbronner R: Midbrain syndrome with eye movement disorder: dramatic improvement after cranioplasty. Strabismus 10:271-277, 2002

19. Grossman N, Shemesh-Jan HS, Merkin V, Gideon M, Cohen A: Deep-freeze preservation of cranial bones for future cranioplasty: nine years of experience in Soroka University Medical Center. Cell Tissue Bank 8:243-246, 2007

20. Horaczek JA, Zierski J, Graewe A: Collagen matrix in decompressive hemicraniectomy. Neurosurgery 63 (1 Suppl 1):ONS176- ONS181, 2008

21. Hutchinson P, Timofeev I, Kirkpatrick P: Surgery for brain edema. Neurosurg Focus 22(5):E14, 2007

22. Hutchinson PJ, Corteen E, Czosnyka M, Mendelow AD, Menon DK, Mitchell P, et al: Decompressive craniectomy in traumatic brain injury: the randomized multicenter RESCUEicp study (www.RESCUEicp.com). Acta Neurochir Suppl (Wien) 96:17-20, 2006

23. Isago T, Nozaki M, Kikuchi Y, Honda T, Nakazawa H: Sinking skin flap syndrome: a case of improved cerebral blood flow after cranioplasty. Ann Plast Surg 53:288-292, 2004

24. Iwama T, Yamada J, Imai S, Shinoda J, Funakoshi T, Sakai N: The use of frozen autogenous bone flaps in delayed cranioplasty revisited. Neurosurgery 52:591-596, 2003

25. Jho DH, Neckrysh S, Hardman J, Charbel FT, Amin-Hanjani S: Ethylene oxide gas sterilization: a simple technique for storing explanted skull bone. Technical note. J Neurosurg 107:440-445, 2007

26. Joffe JM, McDermott PJ, Linney AD, Mosse CA, Harris M: Computer-generated titanium cranioplasty: report of a new 
technique for repairing skull defects. Br J Neurosurg 6:343350,1992

27. Jüttler E, Schwab S, Schmiedek P, Unterberg A, Hennerici M, Woitzik J, et al: Decompressive Surgery for the Treatment of Malignant Infarction of the Middle Cerebral Artery (DESTINY): a randomized, controlled trial. Stroke 38:2518-2525, 2007

28. Kawaguchi T, Hosoda K, Shibata Y, Koyama J: Expanded polytetrafluoroethylene membrane for prevention of adhesions in patients undergoing external decompression and subsequent cranioplasty. Neurol Med Chir (Tokyo) 43:320-324, 2003

29. Kim YW, Yoo DS, Kim DS, Huh PW, Cho KS, Kim JG, et al.: The infection rate in case of cranioplasty according to used materials and skull defect duration J Korean Neurosurg Soc (2 Suppl) 30:216-220, 2001

30. Kriegel RJ, Schaller C, Clusmann H: Cranioplasty for large skull defects with PMMA (Polymethylmethacrylate) or Tutoplast processed autogenic bone grafts. Zentralbl Neurochir 68:182-189, 2007

31. Kumar GS, Chacko AG, Rajshekhar V: Unusual presentation of the "syndrome of the trephined." Neurol India 52:504505,2004

32. Kuo JR, Wang CC, Chio CC, Cheng TJ: Neurological improvement after cranioplasty-analysis by transcranial doppler ultrasonography. J Clin Neurosci 11:486-489, 2004

33. Kyoshima K, Gibo H, Kobayashi S, Sugita K: Cranioplasty with inner table of bone flap. Technical note. J Neurosurg 62:607-609, 1985

34. Lee CH, Cho DS, Jin SC, Kim SH, Park DB: Usefulness of silicone elastomer sheet as another option of adhesion preventive material during craniectomies. Clin Neurol Neurosurg 109:667-671, 2007

35. Lee SC, Wu CT, Lee ST, Chen PJ: Cranioplasty using polymethyl methacrylate prostheses. J Clin Neurosci 16:56-63, 2009

36. Li G, Wen L, Zhan RY, Shen F, Yang XF, Fu WM: Cranioplasty for patients developing large cranial defects combined with post-traumatic hydrocephalus after head trauma. Brain Inj 22:333-337, 2008

37. Liang W, Xiaofeng Y, Weiguo L, Gang S, Xuesheng Z, Fei $\mathrm{C}$, et al: Cranioplasty of large cranial defect at an early stage after decompressive craniectomy performed for severe head trauma. J Craniofac Surg 18:526-532, 2007

38. Liao CC, Kao MC: Cranioplasty for patients with severe depressed skull bone defect after cerebrospinal fluid shunting. J Clin Neurosci 9:553-555, 2002

39. Marchac D, Greensmith A: Long-term experience with methylmethacrylate cranioplasty in craniofacial surgery. J Plast Reconstr Aesthet Surg 61:744-753, 2008

40. Matsuno A, Tanaka H, Iwamuro H, Takanashi S, Miyawaki S, Nakashima M, et al: Analyses of the factors influencing bone graft infection after delayed cranioplasty. Acta Neurochir (Wien) 148:535-540, 2006

41. Missori P, Polli FM, Peschillo S, D’Avella E, Paolini S, Miscusi M: Double dural patch in decompressive craniectomy to preserve the temporal muscle: technical note. Surg Neurol 70:437-439, 2008

42. Moreira-Gonzalez A, Jackson IT, Miyawaki T, Barakat K, DiNick V: Clinical outcome in cranioplasty: critical review in long-term follow-up. J Craniofac Surg 14:144-153, 2003

43. Movassaghi K, Ver Halen J, Ganchi P, Amin-Hanjani S, Mesa J, Yaremchuk MJ: Cranioplasty with subcutaneously preserved autologous bone grafts. Plast Reconstr Surg 117:202206, 2006

44. Muramatsu H, Nathan RD, Shimura T, Teramoto A: Recovery of stroke hemiplegia through neurosurgical intervention in the chronic stage. NeuroRehabilitation 15:157-166, 2000

45. Muramatsu H, Takano T, Koike K: Hemiplegia recovers after cranioplasty in stroke patients in the chronic stage. Int J Rehabil Res 30:103-109, 2007

46. Ng D, Dan NG: Cranioplasty and the syndrome of the trephined. J Clin Neurosci 4:346-348, 1997

47. Oh CH, Park CO, Hyun DK, Park HC, Yoon SH: Comparative study of outcomes between shunting after cranioplasty and in cranioplasty after shunting in large concave flaccid cranial defect with hydrocephalus. J Korean Neurosurg Soc 44:211-216, 2008

48. Osawa M, Hara H, Ichinose Y, Koyama T, Kobayashi S, Sugita Y: Cranioplasty with a frozen and autoclaved bone flap. Acta Neurochir (Wien) 102:38-41, 1990

49. Paşaoğlu A, Kurtsoy A, Koc RK, Kontaş O, Akdemir H, Oktem IS, et al: Cranioplasty with bone flaps preserved under the scalp. Neurosurg Rev 19:153-156, 1996

50. Pate AR: Cranioplasty-a review of 31 cases. Ir Med J 67:635-637, 1974

51. Petty PG: Cranioplasty: a follow-up study. Med J Aust 2:806808, 1974

52. Poetker DM, Pytynia KB, Meyer GA, Wackym PA: Complication rate of transtemporal hydroxyapatite cement cranioplasties: a case series review of 76 cranioplasties. Otol Neurotol 25:604-609, 2004

53. Prolo DJ: Cranial defects and cranioplasty, in Wilkins RH, Rengachary SS (eds): Neurosurgery, ed 2. New York: McGraw-Hill, 1996, pp 2783-2795

54. Raja AI, Linskey ME: In situ cranioplasty with methylmethacrylate and wire lattice. Br J Neurosurg 19:416-419, 2005

55. Replogle RE, Lanzino G, Francel P, Henson S, Lin K, Jane JA: Acrylic cranioplasty using miniplate struts. Neurosurgery 39:747-749, 1996

56. Rish BL, Dillon JD, Meirowsky AM, Caveness WF, Mohr JP, Kistler JP, et al: Cranioplasty: a review of 1030 cases of penetrating head injury. Neurosurgery 4:381-385, 1979

57. Sakamoto S, Eguchi K, Kiura Y, Arita K, Kurisu K: CT perfusion imaging in the syndrome of the sinking skin flap before and after cranioplasty. Clin Neurol Neurosurg 108:583-585, 2006

58. Schiffer J, Gur R, Nisim U, Pollak L: Symptomatic patients after craniectomy. Surg Neurol 47:231-237, 1997

59. Schirmer CM, Ackil AA, Malek AM: Decompressive craniectomy. Neurocrit Care 8:456-470, 2008

60. Scott M, Wycis H, Murtagh F: Long term evaluation of stainless steel cranioplasty. Surg Gynecol Obstet 115:453-461, 1962

61. Segal DH, Oppenheim JS, Murovic JA: Neurological recovery after cranioplasty. Neurosurgery 34:729-731, 1994

62. Shaffrey ME, Persing JA, Shaffrey CI, Delashaw JB, Jane JA: Craniofacial reconstruction, in Apuzzo MLJ (ed): Brain Surgery: Complication and Avoidance Management. New York: Churchill Livingstone, 1993, pp 1373-1398

63. Staffa G, Nataloni A, Compagnone C, Servadei F: Custom made cranioplasty prostheses in porous hydroxy-apatite using 3D design techniques: 7 years experience in 25 patients. Acta Neurochir (Wien) 149:161-170, 2007

64. Stiver SI, Wintermark M, Manley GT: Reversible monoparesis following decompressive hemicraniectomy for traumatic brain injury. J Neurosurg 109:245-254, 2008

65. Suzuki N, Suzuki S, Iwabuchi T: Neurological improvement after cranioplasty. Analysis by dynamic CT scan. Acta Neurochir (Wien) 122:49-53, 1993

66. Vahedi K, Vicaut E, Mateo J, Kurtz A, Orabi M, Guichard JP, et al: Sequential-design, multicenter, randomized, controlled trial of early decompressive craniectomy in malignant middle cerebral artery infarction (DECIMAL Trial). Stroke 38:2506-2517, 2007

67. Vakis A, Koutentakis D, Karabetsos D, Kalostos G: Use of polytetrafluoroethylene dural substitute as adhesion preven- 


\section{Complications of cranioplasty after decompressive craniectomy}

tive material during craniectomies. Clin Neurol Neurosurg 108:798-802, 2006

68. Vanaclocha V, Bazan A, Saiz-Sapena N, Paloma V, Idoate M: Use of frozen cranial vault bone allografts in the repair of extensive cranial bone defects. Acta Neurochir (Wien) 139:653-660, 1997

69. Winkler PA, Stummer W, Linke R, Krishnan KG, Tatsch K: The influence of cranioplasty on postural blood flow regulation, cerebrovascular reserve capacity, and cerebral glucose metabolism. Neurosurg Focus 8(1): e9, 2000

70. Wurm G, Tomancok B, Holl K, Trenkler J: Prospective study on cranioplasty with individual carbon fiber reinforced polymer (CFRP) implants produced by means of stereolithography. Surg Neurol 62:510-521, 2004

71. Yamashima T: Modern cranioplasty with hydroxylapatite ce- ramic granules, buttons, and plates. Neurosurgery 33:939_ 940, 1993

72. Zingale A, Albanese V: Cryopreservation of autogeneous bone flap in cranial surgical practice: what is the future? A grade B and evidence level 4 meta-analytic study. J Neurosurg Sci 47:137-139, 2003

Manuscript submitted February 15, 2009.

Accepted March 30, 2009.

Address correspondence to: Tyler J. Kenning, M.D., 47 New Scotland Avenue, MC-10, Division of Neurosurgery, Albany Medical Center, Albany, New York 12208. email: kennint@mail. amc.edu. 